\title{
Medical device vigilance systems: India, US, UK, and Australia
}

This article was published in the following Dove Press journal:

Medical Devices: Evidence and Research

19 November 2010

Number of times this article has been viewed

\section{Pooja Gupta \\ Manthan D Janodia \\ Puralea $C$ Jagadish \\ Nayanabhirama Udupa}

Manipal Collge of Pharmaceutical Sciences, Manipal University, Manipal, Karnataka, India
Correspondence: Manthan D Janodia Manipal Collge of Pharmaceutical Sciences, Manipal University, Manipal 576104, Karnataka, India Email mdjanodia1978@yahoo.co.in

\begin{abstract}
The term medical device includes a wide category of products ranging from therapeutic medical devices exerting their effects locally such as tissue cutting, wound covering or propping open clogged arteries, to highly sophisticated computerized medical equipment and diagnostic medical devices. To achieve uniformity among the national medical device regulatory systems and increase the access to safe, effective, and clinically beneficial medical technologies, the Global Harmonization Task Force (GHTF) was conceived in 1992 by five members: European Union, United States, Australia, Japan, and Canada. All regulated countries have clearly defined medical devices, as has the GHTF. Although GHTF has tried to achieve harmonization with respect to medical devices, some differences still exist in the national laws of the countries of GHTF. Further, regulated countries have classified medical devices on the basis of their associated risk. In the Indian regulatory system, medical devices are still considered as drugs. In 2006, the Medical Device Regulation Bill was recommended to consolidate laws for medical devices and to establish the Medical Device Regulatory Authority of India. In addition, medical devices are not classified by any Indian regulatory authority. Although India has moved towards harmonizing its medical device regulations with those of regulated countries, this study aims to identify whether India should have a vigilance system in harmony with those of GHTF or develop its own system for medical devices.
\end{abstract}

Keywords: medical device, vigilance, regulatory systems, GHTF, India

\section{Introduction}

The term "medical device" includes a broad category of products ranging from therapeutic medical devices with local applications, such as tissue cutting, wound covering, or propping open clogged arteries, to highly sophisticated computerized medical equipment and diagnostic medical devices. Because these devices vary widely in type and are highly essential for patients' care, their manufacture, distribution, and sale must be regulated to ensure their quality, safety, and efficacy. ${ }^{1}$

The postmarket surveillance of medical devices was initiated in the United States with the enactment of the Food and Drug Administration Modernization Act 1970 under Section 522 for class II and class III devices. ${ }^{2}$ In 1989, the Therapeutic Goods Act provided the legislative basis for uniform national controls over goods used in the prevention, diagnosis, curing, or alleviation of a disease, ailment, defect, or injury in Australia. ${ }^{3}$ In June 1993, the vigilance requirement for medical devices for member states and manufacturers was published as Council Directive 90/385/EEC and 93/42/ EEC, followed by incorporation of amendments of revision 5 of MEDDEV guidance 2.12-1 [1] in 2007 by the European Union. ${ }^{4-7}$ To achieve uniformity between the 
national medical device regulatory systems and to increase the access to safe, effective, and clinically beneficial medical technologies, the Global Harmonization Task Force (GHTF) was conceived in 1992 by five members: European Union, United States, Australia, Japan, and Canada wherein the vigilance of devices was among the study groups. ${ }^{8}$

All regulated countries have distinctly defined medical devices, but GHTF defined a medical device as any instrument, apparatus, implement, machine, appliance, implant, in vitro reagent or calibrator, software, material, or other similar or related article, which is thereby intended to be used by the manufacturer for human beings for one or more of the specific purposes of: ${ }^{1}$

1. Diagnosis, prevention, monitoring, treatment, or alleviation of disease or compensation for an injury

2. Investigation, replacement, modification, or support of the anatomy or of a physiological process

3. Supporting or sustaining life

4. Control of conception

5. Disinfection of medical devices

6. Providing information for medical purposes by means of in vitro examination (such as reagents, calibrators, sample collection kits, control materials, and related instruments) of specimens derived from the human body and which does not achieve its primary intended action in or on the human body by pharmacological, immunological, or metabolic means, but which may be assisted in its function by such means.

The Medicines and Healthcare products Regulatory Agency (MHRA) ${ }^{9}$ has excluded materials used for disinfecting medical devices from the definition, whereas the Therapeutic Goods and Administration (TGA) ${ }^{3}$ has excluded tampons and hospital, household, and commercial grade disinfectants. However, to date, India has considered medical devices as drugs. ${ }^{10}$

\section{Scope and objective}

This study was the result of the examination and comparison of regulations to monitor medical devices in national regulatory authorities: United States, United Kingdom, and Australia (There were 5 founding members of GHTF). The issue of whether India should establish a vigilance system in harmony with those of the GHTF members or start with a clean slate was also taken into account. Hence, the study was initiated to examine the proposed framework, and its implication, for the Indian medical device vigilance system with respect to global harmonization, ie, GHTF.

\section{Plan of study}

During this study, the information was collected through secondary media, ie, the official Websites of the respective regulatory authorities and the knowledge gained by interaction with various industrial professionals in the field of regulatory affairs.

\section{Indian regulatory system}

In the Indian regulatory system, medical devices are considered as drugs by the Ministry of Health and Family Welfare. ${ }^{10}$ In October 2005, the manufacturing of devices came under the control of the Central Licensing Approving Authority. It declared 10 devices, such as cardiac stents, drug-eluting stents, catheters, intraocular lenses, bone cements, heart valves, scalp vein sets, and so on, to be considered drugs and included another 19 sterile medical devices (on March 20, 2009 [on hold]) such as extension tubes, arterial venous fistulas and spinal needles, volume measuring sets, heart lung packs, and so on, under the provisions as such. ${ }^{11}$

In 2006, the Medical Device Regulation Bill ${ }^{12}$ was recommended to consolidate laws for medical devices and to establish the Medical Device Regulatory Authority of India for establishing and maintaining a national system of controls relating to quality, safety, efficacy, and availability of medical devices that are used in India, whether produced in India or elsewhere and exported from India. It was recommended that the provisions of this Act should come into force by December 31, 2009, but the bill was not passed by the Rajya Sabha and and the bill was abolished. It was expected that a definition of medical devices and other likely changes shall be incorporated in Schedule M(III) by 2010. With the initiation of such amendments, it was addressed to include medical device with the Drugs and Cosmetics Act and Rules in a recent press release from the Medical Device Regulatory Authority of India. ${ }^{13}$ In India, the Federation of Indian Chambers of Commerce and Industry (FICCI) is being recognized as the focal point for regulations of medical device. It has been working closely with the Central Drug Standard Control Organization (CDSCO) and Indian medical regulators (both importer and native manufacturers) to increase access to medical device, promoting its manufacturing and streamlining the regulatory process toward global harmonization. ${ }^{14}$

If the product is being imported to India, the importer has to submit postmarket surveillance data including protocol and report not exceeding 5 years for the following: ${ }^{10}$

1. Procedures for distribution of records

2. Complaint handling

3. Adverse incident reporting 


\section{Procedure for product recall}

However, the requirements specified do not require the manufacturer to provide the data for a specified period, but the manufacturers have been required to submit postmarket surveillance data for at least a period of 3-5 years. Recently, the CDSCO has issued the guidelines for Adverse Event Reporting (ADR). ${ }^{15}$

\section{Medical device classification}

Each regulatory authority has classified medical devices in its own way. In general, the basis for medical device classification is: ${ }^{16}$

1. The risk associated with the medical device

2. Manufacturers' intended purpose for the device

3. The device's indications for use

The US Food and Drug Administration (FDA) ${ }^{17}$ has classified medical devices into three classes on the basis of level of control necessary to assure the safety and effectiveness of the device and on the basis of information about marketing requirements and has grouped them into 16 medical specialties:

1. Class I (general controls): eg, elastic bandage and examination gloves

2. Class II (general and special controls): eg, infusion pumps, surgical drapes, and ultrasound imaging systems

3. Class III (general controls and premarket approval): eg, heart valves, and silicone gel-filled breast implants

The $\mathrm{TGA}^{18}$ has classified medical devices into five classes on the basis of set of four classification rules: noninvasive, invasive, active, and special type of devices, which are:

1. Class I (low risk): eg, examination lights and surgical microscopes

2. Class IIa (low-medium risk): eg, warming blankets and electrical acupuncture

3. Class IIb (medium-high risk): eg, infant incubators and external defibrillators

4. Class III (high risk): eg, heparin-coated catheters and biological heart valves

5. Class active implantable medical device (AIMD): eg, contraceptive intrauterine devices

Likewise, the MHRA ${ }^{4,5,19}$ has classified medical devices into three groups:
1. General medical devices

2. AIMD

3. In vitro diagnostic medical devices

The general medical devices were then further classified into four classes as described in Table 1.

Also, the MHRA classified medical devices within a series of 18 rules depending on functions, parts of body treated, and properties of medical devices. If more than one rule applies to a medical device, the higher would be its classification.

In comparison to the regulated countries, medical devices in India are not classified on the basis of risk. Rather, the 10-device category of medical devices has been notified to be regulated as drugs. ${ }^{10}$

\section{Medical device tracking}

Once the medical devices are marketed, they must be tracked up to the end-user for the useful life of the device to facilitate patient notification or recall at the time of any defect or problem with the device. The FDA ${ }^{2,20-23}$ has included medical device tracking as one of its postmarket surveillance activities, but tracking is still in the development stage for inclusion in the TGA vigilance system. ${ }^{24-26}$ For tracking of patients with implantable medical devices, an Implantable Medical Device Tracking Subcommittee (IMDTS) has been developed by TGA. However, the European Medicines Agency has developed the Adverse Incident Tracking System (AITS).

The devices require tracking if they meet statutory requirements according to the FDA act and if the FDA has issued a tracking order. It has also listed some implantable devices that are subjected to tracking. Furthermore, it requires submission of tracking information by the manufacturer, distributor, and user facility. The manufacturer must provide critical information about the devices within 3 or 10 days if a device has not or has been distributed to a patient, respectively. The written records for the useful life of device must also be maintained by the manufacturer and the distributor.

However, in revised MHRA ${ }^{9}$ directives, incidents reported with the device are entered into the AITS database via a user-reporting system. Each incident is given an AITS reference number, and the risk associated with the

Table I MHRA classification of general medical devices

\begin{tabular}{llll}
\hline Class of device & Risk level & Requirements & Example \\
\hline Class I & Low risk & Premarket notification & Dressings \\
Class Ila & Low-medium risk & Certification by notified body & X-ray film \\
Class IIb & Medium-high risk & Certification by notified body & Blood bags, contact lens care products \\
Class III & High risk & Certification by notified body & Bone cement, cardiac stents \\
\hline
\end{tabular}


device is assessed. The adverse incident is then accordingly allocated into one of the five investigation categories, ie, urgent in depth, in depth, standard, information, and others. It is the responsibility of manufacturer or authorized representative to track incident reports, but the information to be tracked is not being specified. In-depth investigations lead to the issue of a Medical Device Alert, whereas standard investigations are initially conducted via a series of standardized letters issued directly by the adverse incident center.

In India, the labeling provisions for devices include identification of lot number or batch number for easy traceability of the device, but maintenance of the tracking records by the manufacturer is not a mandatory requirement. However, in a recent press release by the FICCI, ${ }^{13}$ the Health Minister Dinesh Trivedi had promised to set up a National Health Portal for sharing information in the public domain on standardization and protocols and to ensure that the medical records of all citizens are electronically stored for ease of access by pathologists and doctors for diagnosis and treatment of patients. The statement seemed to represent promising progress toward the establishment of a tracking portal for medical devices.

\section{Adverse event reporting}

The adverse event reporting system has been considered as a tool to improve and protect the health and safety of patients and users, thereby reducing the likelihood of adverse events, to prevent repetition of adverse events, or to alleviate consequences of such repetition. Despite the steps taken by the GHTF to achieve uniformity among adverse event reporting systems, the system still differs in founding member countries.

The $\mathrm{GHTF}^{27}$ provided the guidance on mandatory reporting of adverse events for device manufacturers and voluntary reporting for users. Also, the manufacturer must decide the reportability of adverse events on the basis of information available. The FDA's medical device reporting (MDR) regulations ${ }^{28-31}$ require manufacturers and importers to report serious injuries, deaths, and malfunctions, and user facilities to report serious injuries and deaths. The regulations do not require foreign manufacturer to meet FDA regulations, but if employed, the agent could forward reports and will be viewed as an employee of a foreign firm. The TGA ${ }^{24,32}$ has encouraged the reporting of adverse events not only by the manufacturers and sponsors but also by users. The EEC ${ }^{9,33,34}$ directives include requirements not only for manufacturers or authorized representatives of medical device to report certain types of incidents to a competent authority such as the MHRA, but also for the MHRA to disseminate the information to other competent authorities and the EEC. Also, in India, $\mathrm{CDSCO}^{13}$ considers that an adverse event should be reported by the manufacturer.

\section{Reporting criteria}

The reporting criteria include the following:

- If an event has occurred, and the manufacturer becomes aware of the information

- If it is assessed that the manufacturer's device is associated with the event based on the opinion from the available information

- If the event has led to or might have led to death or serious injury of a patient, user, or other person.

However, the $\mathrm{FDA}^{28-31}$ also requires the manufacturer to report malfunctions and events occurring due to user errors. The TGA ${ }^{24,32}$ also requires the sponsor or manufacturer to report malfunctions. In addition to the above reporting criteria, a manufacturer in India ${ }^{15}$ must also report events that do not require to be reported under regulations, so that trends or patterns of their occurrence can be monitored.

\section{Not-reportable incidents or events}

The regulated countries, along with India, ${ }^{15}$ defined notreportable events similarly with few exceptions. The following events ${ }^{27-45}$ are exempted from reporting in all countries:

- If the deficiency of a device is found by the user before its use and no serious injury has occurred

- If the root cause of the adverse event is due to a patient's pre-existing condition

- If the shelf life or service life of the device was exceeded before its use by a patient

- If the design feature for protection against malfunction complied with the relevant standards and operated correctly

- If the deficiency had a negligible likelihood of causing death or serious injury and had been established and documented as acceptable after risk assessment

- If the side effects are expected and foreseeable from the manufacturer's labeling, are clinically well known, and are documented in the device master record, with an appropriate risk assessment

- If the adverse event was caused by errors of use and abnormal use

As mentioned above, the manufacturer is required to report adverse events occurring in Australia ${ }^{24,32}$ and India if they occur after the issuance of an advisory notice, and their occurrence and frequency are submitted with the annual report, whereas in the United States, ${ }^{35}$ the manufacturer can 
request remedial action exemption (RAE) with or after the submission of one or more 5-day or 30-day initial reports on events. The RAE can be requested if the information received is erroneous; the malfunction does not result in death, serious injury, or other adverse events; death or serious injury did not occur; and another manufacturer has made the device.

\section{Reporting time frame}

Although the reportability of the adverse event is uncertain, the $\mathrm{GHTF}^{27,45}$ requires immediate reporting by the manufacturer of unanticipated death, serious injury, or public health threat and all other reportable events as soon as possible, but no later than 30 elapsed calendar days following the date of awareness of the event. Also, if the adverse events are reported within the first 2 weeks based on an incomplete investigation, it may require a subsequent follow-up report.

The FDA ${ }^{28-31}$ requires reporting of events not only by the manufacturer, whether domestic or foreign, but also by the user facility and distributor. The manufacturer must submit four reports depending on the event reported: first, 30-day reports for death, serious injury, or malfunctions; second, 5-day reports for events requiring immediate remedial action (FDA form 3500A); third, baseline report (FDA form 3417) to provide basic data on the device, subject to MDR report (30 or 5 days); and finally, annual certification (FDA form 3381). The user facility and distributor need to report death and serious injury within 10 working days on FDA form 3500A. The user facility is also required to submit semi-annual reports to FDA (form 3419) from January 1 to July 1. Eventually, form $3500 \mathrm{~A}$ should report events for each device, and only one report must be submitted for the same patient or same event irrespective of the multiple sources of information for an event. Voluntary reports may be submitted at any time for adverse events, product problems, and product use errors through completion of online MedWatch FDA form 3500.

In Australia, ${ }^{24,32}$ although it is the manufacturer who must assess an incident, the sponsor is held accountable for forwarding information about events to the manufacturer and then for forwarding the results of any analysis to the TGA. Hence, the reporting time frame for reporting adverse events is as follows:

1. Sponsor or manufacturer: they must report on form MDIR01 the following events.

a. Death or serious deterioration in the state of health within 10 calendar days

b. Near adverse event or event that did not result in death or serious injury within 30 calendar days c. Serious public health threat or concern and an event that requires prompt remedial action within 48 hours

d. Complaints, malfunctions, and adverse events for class III and AIMD devices that have been reported for the year July 1 and October 1 following the entry of device into the Australian Register of Therapeutic Goods (ARTG) and for the subsequent 3 years

2. Voluntary reporting by users of a suspected health hazard created by a medical device, on form UDIR01.

In certain cases, if all information is not available, the sponsor or manufacturer must provide it later when it is, as additional information along with a statement to the effect that the report is made by the manufacturer and sponsor without prejudice and does not imply any admission of liability for the incident or its consequences. All reports should be submitted to the Coordinator of the Medical Device Incident Report Investigation Scheme of the TGA.

In United Kingdom, ${ }^{33,34}$ the manufacturer is required to report within the time frame relating to the type of incident upon becoming aware that an event has occurred and one of its devices has caused or contributed to the incident, ie,

1. Serious public threat within two calendar days after the date of awareness

2. Death or serious deterioration in state of health within 10 elapsed calendar days after the date of awareness

3. Other incidents, immediately after assessing the link between the device and the event within 30 elapsed calendar days

4. Manufacturer's written acknowledgment of user reports from MHRA to manufacturer within three working days of receiving user report

5. Voluntary reports may be submitted at any time, and may be on the events other than death, serious injury, or malfunction as defined

The manufacturer's incident report form should be used for initial, follow-up, and final incident reports. If the report is made orally, it should be followed by a written report as soon as possible and a statement to the effect that the report is made by the manufacturer without prejudice and does not imply any admission of liability for the incident or its applicability. The manufacturer or authorized representative must submit an initial incident report to MHRA for record and evaluation, followed by final reports, which should not be delayed by incomplete information. Incidents should preferably reported on form MORE, ie, MHRA's Manufacturers' On-line Reporting Environment.

According to the recent amendments directed by the CDSCO,${ }^{15}$ the manufacturer is liable to report unanticipated 
death or serious injury or a serious public health threat within 10 days of becoming aware of the event, and all other reportable events not later than 30 elapsed calendar days. Because of the uncertainty of the reportable events, the manufacturer must report within the expected time frame.

\section{Types of reports}

The reports being submitted are determined on the grounds of stipulated reporting time frames. Thus, GHTF ${ }^{27,45}$ has not recommended any report types for manufacturers. The type of report to be submitted differs among the regulated countries, as the reporting time frame differs. The FDA ${ }^{28-31}$ has determined the manufacturer is required to submit five MDR reports, ie,

1. 30-day report: must contain information on occurrence of death, serious injury, malfunction, and reporting of events via complaint information.

2. 5-day report: is generally submitted for severe, unusual, or unexpected events and those events that require immediate remedial action or for which FDA has made a written request.

3. Baseline report: must accompany the corresponding form $3500 \mathrm{~A}$ when an event involving the device model or device family is reported for the first time, providing basic device identification information. The report can be submitted by model type (one baseline report for each model) or by device family (one baseline report for all models in that family).

4. Supplemental report: must be submitted using form 3500A within 1 month (30 calendar days) after receipt of the additional information. The number of follow-ups would depend on the nature and severity of the event reported.

5. Annual certification: the manufacturer must designate more than one certifying official, each of whom should sign a certification statement for his or her identified organizational component or site. The certification is required to minimize the unintentional reporting errors that have been submitted during the 12-month period. The annual certification has to be submitted during the firm's annual registration date.

However in United Kingdom, ${ }^{33,34}$ the manufacturer or authorized representative can report incidents by submission of following reports:

1. Initial reporting of adverse event to MHRA for record and evaluation

2. Periodic summary reporting: these reports are submitted in an agreed format and frequency for the device and incident between the manufacturer and MHRA after submission of one or more initial reports.

3. Trend reports: these reports must be submitted when there is a significant increase in the rate of already reportable events, incidents that are usually exempted from reporting, and events that are usually not reportable.

4. Final reports

All device complaints, potential use error events, and abnormal use events must be reported and investigated by the manufacturer. The manufacturer must perform the investigation after the initial report in consultation with the user while informing the MHRA of the progress through periodic reports or trend reports as appropriate. If initial assessment involves an alteration of the device that might affect subsequent analysis, the MHRA must be informed before proceeding with alteration.

The TGA ${ }^{24,32}$ also has not determined the distinct report types for reporting adverse events by the manufacturer, whereas $\mathrm{CDSCO}^{15}$ in India has determined notification reports as initial, final, and/or trend report. The choice of report type depends on the availability of applicable data within the appropriate report time.

\section{Vigilance reporting}

The dissemination of information among the National Competent Authorities (NCAs) can help to improve the health and safety of patients, users, and others by reducing the likelihood of repeated similar adverse events. The GHTF ${ }^{36-38}$ defines a vigilance exchange program as a National Competent Authority Report (NCAR) exchange program, which aims at exchanging two types of information: information that may be considered highly sensitive or confidential, and selected public (nonconfidential) information. The countries participating in GHTF receive guidance on how to exchange NCARs. The necessity for NCAR exchange would depend on the seriousness of the incident associated with the device and its extent of global distribution. The criteria for NCAR exchange are as follows:

1. Seriousness

2. Unexpectedness of the incident or event

3. Population that is vulnerable (infants or elderly)

4. Preventability (can useful recommendations be made?)

5. Public concern or outrage, eg, lead aprons containing radioactive material

6. Benefit/risk ratio

7. Lack of scientific data, especially long-term effects

8. Repeated device problems that resurface, eg, heating pads or fires 
9. Written notifications by the NCA to the public (eg, hospitals, physicians)

10. Will active exchange help protect public health or have the manufacturer's actions been sufficient?

The GHTF has posted NCAR forms and reports that could be used for exchanging information directly to the NCAR Secretariat for appropriate global distribution. However, the FDA does not specify a vigilance exchange program as one of its postmarket activities.

In Australia, ${ }^{24,32}$ the NCAR program is obliged to exchange vigilance information with overseas regulatory agencies through its participation in the GHTF and various mutual recognition agreements. Consequently, the information will be exchanged on incidents and events for which corrective action, including recalls, is to be taken and there is a serious risk to the safety of patients or other users, but where no corrective action has yet been established, although measures are under consideration, or where there is not yet a final report from the sponsor.

The dissemination of information to other NCAs is termed NCAR in MHRA., 9,33,34 The information should be copied to the Commission and disseminated to other NCAs to help prevent a recurrence of incidents, depending on the outcome of investigation carried out by the manufacturer and the limitation of their consequences. The information should be disseminated when field safety corrective actions (FSCA) have been performed by the manufacturer or requested by MHRA; changes already initiated in FSCA are requested by MHRA, but corrective action has not yet been taken yet and is under consideration, although there is serious risk to the health of patient/user; and the manufacturer has not provided the final report in a timely manner.

The NCAR should be distributed without delay, but no later than 14 calendar days after the manufacturer has reported, and the manufacturer's report must also be circulated along with the NCAR. In spite of communicating the information to the public, it is recommended to communicate notification directly to the medical practitioner or health professional, unless required.

\section{Records}

Records provide a history of each batch of product, including its distribution, and also of all other relevant circumstances pertinent to the quality of the final product. ${ }^{9,22-24}$ The records should be made or completed at the time each action is taken in such a way that all significant activities concerned are traceable.
Manufacturers are required to establish and maintain written procedures for implementation of the MDR regulation, including the following:

1. Evaluated information that determines the reportability of an event

2. All reports and information of the medical device (MDR) submitted to FDA in either written or electronic form

3. Any information that was evaluated during the preparation of annual certification report(s)

4. Systems that ensure access to information that facilitates timely follow-up and inspection by FDA

5. Investigation protocol that would be followed.

The records related to an event (whether reportable or not) must be maintained for 2 years from the date of the event or a period equivalent to the expected life of the device, whichever is longer.

The sponsors marketing medical devices in Australia are required to keep distribution records and retain them for 5 years after the last product has been made and to provide the records, or copies of the records, when requested by the TGA. The sponsors should maintain records for the products manufactured by them in accordance with the following:

1. A system should be in operation whereby the complete and up-to-date histories of all batches of components from the starting materials to the finished products can be progressively recorded.

2. The system should allow the determination of utilization and disposal of device components.

All sponsors should maintain records of problem reports received about each device and problem reports evaluated by competent personnel, and the appropriate action taken should also be shown in the records.

For MHRA, the manufacturers must establish a documented procedure for a feedback system and for operating in compliance with the standards of a "Medical device Quality Management System". The documented procedure must aim at providing the following:

1. Early warnings of quality problems and implementation of timely corrective and preventive actions

2. Records of adverse incident reports received from any source for the device associated with the incident. The procedure must also detail the evaluation of each report and the consequent action taken.

3. Review of customer or user complaints, such as customer or user surveys, literature reviews, postmarket clinical follow-up, and so on, depending on the nature of device 
4. Records of manufacturing by date and batch or serial number and supply of medical devices directly to users and distributors

5. For active implantable devices, the code should be recorded.

These records should be retained throughout the specified lifetime of the device for which an FSCA may be necessary.

\section{Enforcement actions}

To ensure the supply of safe, efficacious, and quality medical devices in the Australian market and establishment and maintenance of national systems of controls, the vigilance program in $\mathrm{TGA}^{39,40}$ has incorporated the following enforcement actions:

1. Offences and penalties, eg, failure to notify adverse events (section 41MP), with maximum penalties of $\mathrm{A} \$ 44,000$ for individuals and A $\$ 220,000$ for corporations

2. Suspension or cancellation of the medical device from the ARTG (parts 4-6 of the act)

3. Recall of medical devices supplied to either batch level or all medical devices

However, the device can be suspended for a maximum period of 6 months, which can be extended for a further 6 months (maximum) if the TGA is satisfied that the manufacturer has demonstrated they are correcting the issue that led to the suspension. If this extension period expires, then the entry on the ARTG is automatically cancelled. The TGA will cancel the products from the register only in those cases where there has been a severe breach of the law or, more often, where there is a safety concern associated with the use of the product. The notice of the cancellation will be published in the Commonwealth Gazette.

For the compliance with UK medical device regulations, MHRA $^{33,34}$ investigates any complaints about the products marked or not marked with the CE mark, inspects the manufacturer's facilities in case of breach of regulations, and investigates the results of vigilance reports. MHRA has defined a range of enforcement powers under the Consumer Protection Act 1987, Medical Device Regulations 2002, and General Product Safety Regulations 2005.

\section{Consumer Protection Act 1987}

1. Offence against safety regulations

2. Prohibition notices

3. Notices to warn

4. Suspension notices

5. Test purchase

6. Forfeiture orders

\section{Medical Device Regulations 2002}

1. Compliance notice

2. Restriction notice

Under the General Product Safety Regulations 2005 a recall notice is issued on the grounds that the device is a dangerous product and has already been supplied or made available to the consumers.

\section{Recall}

While marketing a device, the manufacturer distributor, or consumer might report complaints as some quality defects. If a complaint about a defect is not justified, then it is considered a failure of the quality system and immediate corrective action is undertaken by a product recal.

The guidelines of $\mathrm{MHRA}^{42}$ and $\mathrm{GHTF}^{43,44}$ have termed recall a FSCA to reduce the risk of harm to patients, operators, or others or to minimize the recurrence of the event. The FSCA would include the following actions:

1. Return of a medical device to the manufacturer or its representative (which is termed recall)

2. Device modification

3. Device exchange

4. Device destruction

5. Advice given by manufacturer regarding the use of the device

The MHRA $^{42}$ has recommended timescales to issue a FSCA (Table 2).

The FSCA could include actions such as return of a medical device to supplier; device modification, exchange or destruction; retrofit by the purchaser of manufacturer's modification or design change; and any advice being given by the manufacturer on the use of the device. However, the manufacturer must distribute a field safety notice (FSN) by appropriate means such as by conformation of receipt. The FSN should be sent in the official language of the recipient, and a common layout technique should be used by the manufacturer to highlight the most important parts of the letter and to have a clearly arranged notice. The FSN itself should include the following items:

Table 2 Timescales to issue a FSCA

\begin{tabular}{ll}
\hline Draft field & Minimum of $48 \mathrm{~h}$ for MHRA \\
safety notice & to comment \\
Response to MHRA & 21 working days or as specifically requested \\
on queries concerning & in writing by MHRA, eg, when a serious \\
FSCA & public threat \\
\hline
\end{tabular}

Abbreviation: FSCA, field safety corrective actions. 
1. A clear title like "Urgent Safety Notice" on the notice itself, on the envelope if sent by mail, and as the subject line if sent by email or fax

2. The intended audience: clear statement about the intended recipient of the notice

3. Concise description of subject device (model, batch, or serial number)

4. A factual statement explaining the reasons for the FSCA

5. A clear description of the hazards associated with the specific failure of the device and, where appropriate, the likelihood of occurrence, being mindful of the intended audience

6. The recommended action to be taken by the recipient of the FSN

7. Time frames by which the action should be taken by the manufacturer and user, where appropriate

8. Designated contact point for the recipient of the FSN to use to obtain further information.

The notice must also include a request to inform customers or patients who received the product. If relevant, the notice must also include a request for the details of any affected devices that have been transferred to other organizations or been destroyed to be given to the manufacturer so that follow-up can take place and a request for a copy of the FSN to be passed on to the organization to which the device has been transferred. Manufacturers using a unique reference number to identify the FSCA should include this in the FSN, or include a date.

In the United States ${ }^{9}$ and Australia, ${ }^{41}$ medical device recalls are usually conducted voluntarily by the manufacturer, but in rare instances when the manufacturer or importer (foreign manufacturer) fails to voluntarily recall a device that is a risk to health or the device is removed from ARTG, the respective authority could issue a recall order to the manufacturer. However, the recall does not include market withdrawal or a stock recovery. Also in Australia, the manufacturers, sponsors, and distributors are required to report the necessity for a recall on a Medical Device Incident Report form notifying not only serious problems for devices but also any kind of tampering with the medical device. But if the sponsor fails to carry out the mandatory recall and fails to notify a safety-related recall, then they are subjected to substantial fines.

The recalls have been classified on the same principles (associated relative health hazard) by both FDA and TGA as follows:

1. Class I: where severe adverse health consequences or death are likely
2. Class II: where temporary or medically reversible health consequences are likely

3. Class III: where use or exposure to the offending product will not likely cause adverse health consequences.

Class I or class II recalls are considered to be urgent safety-related recalls, whereas class III recalls are considered to be routine nonsafety-related recalls. In addition, the TGA has classified recalls on the basis of the following:

1. The incidence of complaints

2. Distribution networks

3. Recovery procedures

4. Resources for corrective action

5. Availability of alternative products

The TGA and FDA have also defined the elements of recall strategy, including classification of recall; necessity of initiating a recall; level (or depth) of a recall, ie, wholesale, retail, hospital, or consumer level; significance of the hazard (if any); the channels by which the goods have been distributed; and the level to which distribution has taken place. The manufacturer must also specify the method used and the level of consignees' communication for recall. These levels have been specified by the FDA as below:

1. Level A: $100 \%$ of the total number of consignees to be contacted

2. Level B: some percentage, ie, $10 \%-100 \%$ of the total number of consignees to be contacted on a case-by-case basis

3. Level C: $10 \%$ of the total number of consignees to be contacted

4. Level D: $2 \%$ of the total number of consignees to be contacted

5. Level E: no effectiveness checks

The manufacturer marketing devices in the United States should submit regular a recall status report, whose frequency is decided by the FDA, but generally the reporting interval is between 2 and 4 weeks. According to TGA, the sponsor should provide the Australian Recalls Coordinator with an interim and a final report on the recall at 2 and 6 weeks after the implementation of the recall or at other agreed times, to establish the effectiveness of the recall. The MHRA has recommended inclusion of the following in the follow-up progress of FSCA report:

1. Monitoring of the extent of notification and reconciliation of FSCA

2. In-house corrective action to prevent the recurrence of problem

The final FSCA report should also incorporate validation of corrective measures. 


\section{Result}

In 1992, although the GHTF was established with a view to achieve uniformity in medical device regulations globally among founding members, the regulations of the United States, United Kingdom, and Australia still differ. Also taking into account the guideline issued by CDSCO, it was observed that the regulators in India have moved towards harmonizing the vigilance system with those of regulated countries. Major differences are still apparent, however (see Table 3).

\section{Conclusion}

Despite efforts by the founding members of GHTF to achieve uniformity for medical device regulations globally since 1992, these regulations still differ. Like ICH, these major differences need to be eliminated to facilitate the introduction by manufacturers of emerging technologies for medical devices in both developed and developing countries.

Taking into account these differences, the question remains as to what is the aim of harmonization. The consensus should be that it should aim at establishing regulations that

Table 3 Differences in vigilance systems of US, UK, Australia, and India

\begin{tabular}{|c|c|c|c|c|}
\hline $\begin{array}{l}\text { Parameters } \\
\text { of countries }\end{array}$ & FDA & TGA (Australia) & MHRA & CDSCO (India) \\
\hline $\begin{array}{l}\text { Definition of } \\
\text { medical device }\end{array}$ & $\begin{array}{l}\text { Includes all instruments, } \\
\text { appliances, materials, } \\
\text { machines, in vitro diagnostic } \\
\text { agents, implants, software, } \\
\text { accessories, and disinfectants }\end{array}$ & $\begin{array}{l}\text { Excludes tampons and hospital, } \\
\text { household, and commercial-grade } \\
\text { disinfectants }\end{array}$ & $\begin{array}{l}\text { Excludes materials used } \\
\text { for disinfection of medical } \\
\text { devices }\end{array}$ & $\begin{array}{l}\text { I0-device category regulated } \\
\text { as drug }\end{array}$ \\
\hline $\begin{array}{l}\text { Medical device } \\
\text { classification }\end{array}$ & $\begin{array}{l}3 \text { classes: class I, class II, and } \\
\text { class III }\end{array}$ & $\begin{array}{l}5 \text { classes: class I, classes Ila and IIb, } \\
\text { class III, and class AIMD }\end{array}$ & $\begin{array}{l}4 \text { classes: class I, class Ila, } \\
\text { class Ilb, and class III }\end{array}$ & No defined classes for devices \\
\hline $\begin{array}{l}\text { Basis of } \\
\text { classification }\end{array}$ & $\begin{array}{l}\text { Level of control } \\
\text { Medical specialties }\end{array}$ & Classification rules & Classification rules & NA \\
\hline $\begin{array}{l}\text { Postmarketing } \\
\text { surveillance } \\
\text { activities }\end{array}$ & $\begin{array}{l}\text { Medical device tracking } \\
\text { MDR } \\
\text { MDR event files, records, } \\
\text { and written procedures } \\
\text { Complaint handling } \\
\text { Recall procedure and seizures }\end{array}$ & $\begin{array}{l}\text { Adverse event reporting } \\
\text { Vigilance exchange program } \\
\text { Enforcement activities } \\
\text { Distribution records } \\
\text { Audits }\end{array}$ & $\begin{array}{l}\text { Adverse event reporting } \\
\text { FSCA and field safety notices } \\
\text { Investigations } \\
\text { Enforcement } \\
\text { Postmarket clinical follow-up } \\
\text { Records }\end{array}$ & $\begin{array}{l}\text { Adverse event reporting } \\
\text { For importers } \\
\text { complaint handling } \\
\text { adverse event reporting } \\
\text { procedure for distribution } \\
\text { of records } \\
\text { procedure for recall }\end{array}$ \\
\hline $\begin{array}{l}\text { Medical device } \\
\text { tracking }\end{array}$ & $\begin{array}{l}\text { Have established tracking } \\
\text { system since } 1993\end{array}$ & $\begin{array}{l}\text { IMDTS developed recently } \\
\text { for tracking of patients with } \\
\text { implantable medical devices }\end{array}$ & $\begin{array}{l}\text { AITS developed to } \\
\text { investigate the failure modes } \\
\text { of the device by assessment } \\
\text { of user reports }\end{array}$ & $\begin{array}{l}\text { In labeling provisions, the lot } \\
\text { number/batch number for } \\
\text { device is mandatory for easy } \\
\text { traceability }\end{array}$ \\
\hline $\begin{array}{l}\text { Who need to } \\
\text { report } A E\end{array}$ & $\begin{array}{l}\text { Manufacturers, importers, user } \\
\text { facilities, users, distributors, } \\
\text { and health professionals }\end{array}$ & $\begin{array}{l}\text { Manufacturers, sponsors, users, } \\
\text { health professionals, and TGA }\end{array}$ & $\begin{array}{l}\text { Manufacturers, users, health } \\
\text { professionals, authorized } \\
\text { representatives, and MHRA }\end{array}$ & Manufacturers only \\
\hline $\begin{array}{l}\text { Criteria for } \\
\text { reporting }\end{array}$ & $\begin{array}{l}\text { Death or serious injury } \\
\text { Device malfunctions } \\
\text { User error } \\
\text { Injury/illness requiring medical } \\
\text { intervention }\end{array}$ & $\begin{array}{l}\text { Event has occurred } \\
\text { Medical device's association with } \\
\text { the event } \\
\text { Event led/might lead to death/ } \\
\text { serious injury }\end{array}$ & $\begin{array}{l}\text { Event has occurred } \\
\text { Medical device's association } \\
\text { with the event } \\
\text { Event led/might lead to } \\
\text { death/serious injury }\end{array}$ & $\begin{array}{l}\text { Event has occurred } \\
\text { Medical device's association } \\
\text { with the event } \\
\text { Event led/might lead to death/ } \\
\text { serious injury }\end{array}$ \\
\hline $\begin{array}{l}\text { Not-reportable } \\
\text { incidents/events }\end{array}$ & $\begin{array}{l}\text { Manufacturers can apply for } \\
\text { RAE, eg, } \\
\text { Erroneous information } \\
\text { When other manufacturer } \\
\text { makes the device }\end{array}$ & $\begin{array}{l}\text { User-detected deficiencies } \\
\text { Root cause of the adverse event } \\
\text { is due to the patients' pre- } \\
\text { existing condition } \\
\text { Exceeded service life of device } \\
\text { Likelihood of adverse event is } \\
\text { acceptable after risk assessment } \\
\text { Side effects clearly identified in } \\
\text { the manufacturer's labeling and } \\
\text { documented in device master } \\
\text { record }\end{array}$ & $\begin{array}{l}\text { User-detected deficiencies } \\
\text { Root cause of the adverse } \\
\text { event is due to the patients' } \\
\text { pre-existing condition } \\
\text { Exceeded service life of device } \\
\text { Likelihood of adverse event } \\
\text { is acceptable after risk } \\
\text { assessment } \\
\text { Side effects clearly identified in } \\
\text { the manufacturer's labeling and } \\
\text { documented in device master } \\
\text { record }\end{array}$ & $\begin{array}{l}\text { User-detected deficiencies } \\
\text { Root cause of the adverse } \\
\text { event is due to the patients' } \\
\text { preexisting condition } \\
\text { Exceeded service life of device } \\
\text { Likelihood of adverse event is } \\
\text { acceptable after risk assessment } \\
\text { Side effects clearly identified in } \\
\text { the manufacturer's labeling and } \\
\text { documented in device master } \\
\text { record }\end{array}$ \\
\hline
\end{tabular}

(Continued) 
Table 3 (Continued)

\begin{tabular}{|c|c|c|c|c|}
\hline $\begin{array}{l}\text { Parameters } \\
\text { of countries }\end{array}$ & FDA & TGA (Australia) & MHRA & CDSCO (India) \\
\hline $\begin{array}{l}\text { Reporting time } \\
\text { frame }\end{array}$ & $\begin{array}{l}\text { Manufacture: death, serious } \\
\text { injury, and malfunctions - } \\
30 \text { calendar days, and events } \\
\text { requiring immediate remedial } \\
\text { action - } 5 \text { working days } \\
\text { User facility: death and serious } \\
\text { injury - } 10 \text { working days } \\
\text { Distributors and importers: } \\
\text { death, serious injury, and } \\
\text { malfunction to manufacturer - } \\
10 \text { working days }\end{array}$ & $\begin{array}{l}\text { Death/serious deterioration - } \\
10 \text { calendar days } \\
\text { Reportable near adverse event - } \\
30 \text { calendar days } \\
\text { Serious public health threat } \\
\text { requiring remedial action - } 48 \mathrm{~h}\end{array}$ & $\begin{array}{l}\text { Serious public threat - } \\
2 \text { calendar days } \\
\text { Death/serious deterioration } \\
\text { - } 10 \text { elapsed calendar days } \\
\text { Other incidents - } 30 \text { elapsed } \\
\text { calendar days } \\
\text { After receiving user reports } \\
\text { from MHRA, reporting } 3 \\
\text { working days }\end{array}$ & $\begin{array}{l}\text { Unanticipated death or serious } \\
\text { injury within } 10 \text { days } \\
\text { All other reportable events not } \\
\text { later than } 30 \text { elapsed calendar } \\
\text { days }\end{array}$ \\
\hline Types of report & $\begin{array}{l}\text { 30-day reports } \\
5 \text {-day reports } \\
\text { Baseline reporting } \\
\text { Supplemental reporting } \\
\text { Annual reports }\end{array}$ & $\begin{array}{l}\text { Adverse event report for each } \\
\text { incident or medical device } \\
\text { Annual report }\end{array}$ & $\begin{array}{l}\text { Initial reporting of } \\
\text { adverse events } \\
\text { Final reports } \\
\text { Periodic summary reporting } \\
\text { Trend reporting }\end{array}$ & $\begin{array}{l}\text { Initial reporting } \\
\text { Trend reporting } \\
\text { Final reporting }\end{array}$ \\
\hline $\begin{array}{l}\text { Applicable } \\
\text { forms }\end{array}$ & $\begin{array}{l}\text { Form } 3500 \text { - online } \\
\text { Form } 3500 \text { A for } \\
\text { manufacturers, importers, } \\
\text { and distributors } \\
\text { Form } 3419 \\
\text { Form } 3417 \\
\text { Form } 3381\end{array}$ & $\begin{array}{l}\text { Form MDIROI } \\
\text { Form UDIROI - online }\end{array}$ & $\begin{array}{l}\text { Manufacturer's incident } \\
\text { report form } \\
\text { Online reporting for } \\
\text { manufacturers by MORE }\end{array}$ & Adverse event reporting form \\
\hline $\begin{array}{l}\text { Vigilance } \\
\text { exchange }\end{array}$ & NA & $\begin{array}{l}\text { With overseas regulatory } \\
\text { agencies }\end{array}$ & $\begin{array}{l}\text { Exchange information for } \\
\text { similar incidents and for } \\
\text { FSCA within and outside }\end{array}$ & Not defined \\
\hline $\begin{array}{l}\text { Vigilance } \\
\text { exchange form }\end{array}$ & NA & No & Yes & NA \\
\hline Records & $\begin{array}{l}\text { AE records } \\
\text { Evaluation records } \\
\text { Records for follow-up and } \\
\text { inspection } \\
\text { Investigation protocol } \\
\text { Copies of test, laboratory } \\
\text { reports, and service records }\end{array}$ & $\begin{array}{l}\text { Distribution records } \\
\text { Records for products } \\
\text { manufactured } \\
\text { Records of problem report, } \\
\text { its evaluation, and appropriate } \\
\text { action taken }\end{array}$ & $\begin{array}{l}\text { AE records } \\
\text { Evaluation records } \\
\text { Customer/user complaint } \\
\text { record } \\
\text { Records for products } \\
\text { manufactured } \\
\text { Records of distributors } \\
\text { CAPA records }\end{array}$ & $\begin{array}{l}\text { A mandatory specification for } \\
\text { importers only }\end{array}$ \\
\hline Recall/FSCA & $\begin{array}{l}\text { Manufacturers need to initiate } \\
\text { recall }\end{array}$ & Sponsors need to initiate recall & $\begin{array}{l}\text { Manufacturers need to } \\
\text { initiate recall }\end{array}$ & $\begin{array}{l}\text { A mandatory specification for } \\
\text { importers only }\end{array}$ \\
\hline $\begin{array}{l}\text { Recall } \\
\text { communication }\end{array}$ & $\begin{array}{l}\text { Telephone calls, telegrams, } \\
\text { and mailgrams } \\
\text { First class letters approved } \\
\text { by FDA } \\
\text { General public warning } \\
\text { Public warning through } \\
\text { specialized news media }\end{array}$ & $\begin{array}{l}\text { Recall letters approved within } \\
48 \text { hours of recall agreement } \\
\text { Paid advertisements to consumer/ } \\
\text { retail level approved by TGA }\end{array}$ & $\begin{array}{l}\text { FSN approved by MHRA as } \\
\text { per specified format within } \\
48 \text { hours of FSCA agreement } \\
\text { In case of urgency, through } \\
\text { telephone, fax, or by a visit }\end{array}$ & - \\
\hline
\end{tabular}

Abbreviations: AE, adverse event; AIMD, active implantable medical device; AITS, Adverse Incident Tracking System; CAPA, corrective and preventive actions; CDSCO, Central Drug Standard Control Organization; FDA, Food and Drug Administration; FSCA, field safety corrective actions; FSN, field safety notice; IMDTS, Implantable Medical Device Tracking Subcommittee; MDR, medical device reporting; MHRA, Medicines and Healthcare products Regulatory Agency; RAE, remedial action exemption; TGA, Therapeutic Goods and Administration.

not only alleviate and improve patients' health but also promote international trade. To this effect, India has begun to introduce an adverse event reporting system that is uniform with that of regulated countries. Hence, in order to maintain a national system of controls for medical devices, CDSCO should promote the adoption of existing vigilance systems of regulated countries and incorporate timely amendments. For example,

1. The regulators should define clearly the medical device and classify the devices on the basis of risk involved. 
2. Like the United States, the reporting time frame must include not only manufacturers but also the user facility and distributors.

3. The regulations should include distinct tracking provisions for tracking of devices through to end-users, such as inclusion of General Medical Device Nomenclature codes.

4. CDSCO should also incorporate a vigilance exchange program.

5. Unlike the FDA, CDSCO should define distinctly the enforcement actions including a recall system in case of breach of regulations.

6. CDSCO should also indicate a specific format for FSCA and FSN.

7. CDSCO should also establish an online adverse event reporting system.

\section{Disclosure}

The authors report no conflicts of interest in this work.

\section{References}

1. Information document concerning the definition of the term "Medical Device". 2005 May. http://www.ghtf.org/sg1/sg1-final.html. Accessed 2009 Oct 14.

2. Guidance for Industry and FDA Staff: postmarket surveillance under section 522 of the Federal Food, Drug and Cosmetic Act. 2006 Apr. http://www.fda.gov/downloads/MedicalDevices/DeviceRegulatio nandGuidance/GuidanceDocuments/ucm072564.pdf. Accessed 2009 Aug 8.

3. Australian medical device guidelines: an overview of the new medical devices regulatory system. http://www.tga.gov.au/docs/html/ devguid1.htm

4. European Commission Enterprise and Industry: Medical Devices. Cited 2010 Apr 27. http://ec.europa.eu/enterprise/sectors/medical-devices/ index_en.htm. Accessed 2009 Sep 25.

5. Council Directive 93/42/EEC concerning medical devices. 1993 Jun. Cited 2009 Sep 5. http://ec.europa.eu/enterprise/sectors/ medical-devices/documents/revision/index_en.htm

6. Registration of medical devices. http://www.mhra.gov.uk/Howweregu late/Devices/Registrationofmedicaldevices/index.htm. Accessed 2010 Apr 29.

7. Council Directive on the approximation of laws of the member states relating to active implantable medical devices (90/385/EEC). 1990 Jun 20. Cited 2010 Mar 15. http://eur-lex.europa.eu/LexUriServ. do? ?ri $=$ CONSLEG:1990L0385:20071011:en:PDF.

8. About GHTF. http://www.ghtf.org/about/. Accessed 2009 Oct 12.

9. Directives Bulletin No. 3: guidance on the operation of EU vigilance system in UK. 2008 Sep. http://www.mhra.gov.uk/Publications/Regulatoryuidance/Devices/DirectivesBulletins/CON2033888. Accessed 2009 Aug 11.

10. Guidelines for import and manufacture of medical devices. http://www. cdsco.nic.in/medical\%20device\%20 A42.html. Accessed 2009 Sep 18.

11. Clarification with regard to control of various medical devices. 2009 Mar. http://www.cdsco.nic.in/MEDICAL\%20DEVICE\%20page.htm. Accessed 2009 Dec 12.

12. The Medical Device Regulations Bill, 2006. http://dst.gov.in/whats_ new/whats_new07/MDRA-Act.pdf. Accessed 2009 Aug 29.

13. National Workshop: Medical Device Regulations in India; 2010 July 12. New Delhi: FICCI.
14. Medical devices and equipment. http://www.ficci.com/sector-details. asp? secid $=76$. Accessed Cited 2009 Dec 16 .

15. Adverse event reporting. Central Drugs Standard Control Organisation. http://CDSCO-AER/Meddevice. Accessed 2010 Jul 19.

16. Principles of medical devices classification. 2006 June. http://www. ghtf.org/GHTF/SG1/N15:2006. Accessed 2009 Oct 14.

17. Device classification. 2009 Jul. http://www.fda.gov/MedicalDevices/ DeviceRegulationandGuidance/Overview/ClassifyYourDevice/default. htm. Accessed 2009 Sep 30.

18. Australian Medical Device Guidance Document Number 25: classification of medical device. $2005 \mathrm{Jan}$. http://www.tga.gov.au/docs/ pdf/devguid25.pdf. Accessed 2009 Aug 12.

19. Bulletin No. 10: the classification rules. 2006 Feb. http://www.mhra. gov.uk/home/groups/es-era/documents/publication/con007495.pdf. Accessed 2009 Sep 28.

20. Medical device tracking. 2009 May. http://www.fda.gov/DeviceRegu lationandGuidance/PostmarketRequirements/MedicalDeviceTracking/ default.htm-32k-2008-10-15. Accessed 2009 Aug 8.

21. Medical device tracking: guidance for Industry and FDA Staff. 2003 May. http://www.fda.gov/MedicalDevices/DeviceRegulationandGuid ance/GuidanceDocuments/ucm071756.htm-67k-2009-01-29. Accessed 2009 Aug 8.

22. Medical device tracking requirements. 2008 Apr. http://www.fda.gov/ MedicalDevices/DeviceRegulationandGuidance/GuidanceDocuments/ ucm071756.htm-67k-2009-01-29. Accessed 2009 Aug 8.

23. Inspection of medical device manufacturers: Attachment D: summary of tracking requirements. 2009 May. http://www.fda.gov/MedicalDe vices/DeviceRegulationandGuidance/GuidanceDocuments/ ucm149673.htm. Accessed 2009 Aug 15.

24. Australian medical device guidelines: postmarket activities. 2003. http:// www.tga.gov.au/pdf/devguid11.pdf. Accessed 2009 Aug 14.

25. Regulation of medical devices. 2009 Feb. http://www.tga.gov.au/ devices/devices.htm. Accessed 2009 Aug 14.

26. MDEC Meeting 2005/2. 2005 Jun. http://www.tga.gov.au/docs/html/ $\mathrm{mdec} / \mathrm{mdec} 20052 . \mathrm{htm}$. Accessed 2009 Aug 16.

27. Medical devices post market surveillance: global guidance for adverse event reporting for medical devices. 2006 Nov. http://www.ghtf.org/ GHTF/SG2/N54R8:2006. Accessed 2009 Oct 25.

28. Medical device reporting for manufacturers. 1997 Mar. http://www. fda.gov/MedicalDevices/DeviceRegulationandGuidance/Guidance Documents/ucm094529.htm. Accessed 2009 Aug 10.

29. Medical device reporting: manufacturer reporting requirements. 2008 Apr. http://www.fda.gov/MedicalDevices/DeviceRegulatio nandGuidance. Accessed 2009 Aug 10.

30. Reporting adverse events (medical devices). 2009 Aug. http://www. fda.gov/MedicalDevices/DeviceRegulationandGuidance/Postmarket Requirements/ReportingAdverseEvents/default.htm. Accessed 2009 Aug 10

31. Medical device reporting: user facility reporting requirements. 2008 Apr. http://www.fda.gov/downloads/MedicalDevices/Device RegulationandGuidance/GuidanceDocuments/UCM095266.pdf. Accessed 2009 Aug 11.

32. Australian medical device guidelines: obligations and responsibilities of medical device manufacturers and sponsors. 2003. http://www.tga. gov.au/docs/html/devguid20.htm. Accessed 2009 Aug 14.

33. Making medical device vigilance more effective. 2007 Nov. http://www. mhra.gov.uk/NewsCentre/CON2033159. Accessed 2009 Aug 11.

34. New medical devices vigilance guidance system MEDDEV version 5. http://www.mhra.gov.uk/Publications/Regulatoryuidance/Devices/ DirectivesBulletins/CON2033888. Accessed 2009 Aug 15.

35. Medical device reporting - remedial action exemption; guidance for FDA and Industry. 2001 Sep. http://www.fda.gov/MedicalDevices/ DeviceRegulationandGuidance/GuidanceDocuments/ucm071354.htm. Accessed 2009 Aug 15.

36. Guidance on how to handle information concerning vigilance reporting related to medical devices. 1999 Jun. http://www.ghtf.org/GHTF-SG2N008R4. Accessed 2009 Oct 8. 
37. Medical devices: post market surveillance: National Competent Authority Report Exchange Criteria and Report Form. 2009 Feb. http:// www.ghtf.org/GHTF/SG2/N79R11:2009. Accessed 2009 Oct 8.

38. Application requirements for participation in the GHTF National Competent Authority Report Exchange Program. 2009 Jul. http://www. ghtf.org/GHTF/SG2/ N38R19:2009. Accessed 2009 Oct 25.

39. Offences/enforcement/illegal supply of medical devices. 2006 Oct. http://www.tga.gov.au/devices/fs-offences.htm. Accessed 2009 Aug 16.

40. Suspension and cancellation of a medical device entry in the Australian Register of Therapeutic Goods (ARTG). 2006 Oct. http://www.tga.gov. au/devices/fs_suspcanc.htm. Accessed 2009 Aug 16.

41. Uniform recall procedure for therapeutic goods. 2004. http://www.tga. gov.au/docs/html.urptg.htm. Accessed 2009 Aug 16.
42. Recalls, corrections and removals (devices). 2009 Jul. Available from: http://www.fda.gov Statutory Instrument 2002 No.618: The Medical Device Regulations 2002. 2002 Jun. Cited 2009 Oct 7. http://www. mhra.gov.uk/. Accessed 2009 Sep 30.

43. Medical devices post market surveillance: content of field safety notices. 2006 Jun. Available from: http:www.ghtf.org/ GHTF/SG2/N57R8:2006. Accessed 2009 Oct 8.

44. Medical devices post market surveillance: content of field safety notices. 2006 Jun. http://www.ghtf.org/GHTF/SG2/N57R8:2006. Accessed 2009 Oct 25.

45. Comparison of the Device Adverse Reporting Systems in USA, Europe, Australia, Canada and Japan. 2002 May. http://www.ghtf.org/GHTF/ SG2/N6R3:2002. Accessed 2009 Sep 2.

\section{Publish your work in this journal}

Medical Devices: Evidence and Research is an international, peerreviewed, open access journal that focuses on the evidence, technology, research, and expert opinion supporting the use and application of medical devices in the diagnosis, treatment and management of clinica conditions and physiological processes. The identification of novel devices and optimal use of existing devices which will lead to improved clinical outcomes and more effective patient management and safety is a key feature. The manuscript management system is completely online and includes a quick and fair peer-review system. Visit http://www. dovepress.com/testimonials.php to read real quotes from authors.

Submit your manuscript here: http://www.dovepress.com/medical-devices-evidence-and-research-journal 